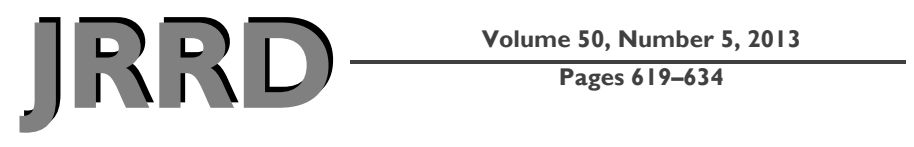

\title{
Load applied on bone-anchored transfemoral prosthesis: Characterization of a prosthesis-A pilot study
}

\author{
Laurent Frossard, PhD; ${ }^{1-2 *}$ Eva Häggström, CPO ${ }^{3-4}$ Kerstin Hagberg, PhD; ${ }^{3-5}$ Rickard Brånemark, MD, \\ $\mathbf{P h D}^{4-5}$ \\ ${ }^{1}$ Group of Research on Adapted Physical Activities, Université du Québec à Montréal, Montréal, Canada; ${ }^{2}$ Marie \\ Enfant Rehabilitation Centre of CHU Sainte-Justine, Montréal, Canada; ${ }^{3}$ Department of Prosthetics and Orthotics, \\ Sahlgrenska University Hospital, Gothenburg, Sweden; ${ }^{4}$ Department of Orthopaedics, Institute of Clinical Sciences, \\ Sahlgrenska Academy, University of Gothenburg, Gothenburg, Sweden; ${ }^{5}$ Centre of Orthopaedic Osseointegration, \\ Sahlgrenska University Hospital, Gothenburg, Sweden
}

\begin{abstract}
The objectives of this study were to (1) record the inner-prosthesis loading during activities of daily living (ADLs), (2) present a set of variables comparing loading data, and (3) provide an example of characterization of two prostheses. The load was measured at $200 \mathrm{~Hz}$ using a multi-axial transducer mounted between the residuum and the knee of an individual with unilateral transfemoral amputation fitted with a bone-anchored prosthesis. The load was measured while using two different prosthetic knees, mechanical (PRO1) and microprocessor-controlled (PRO2), during six ADLs. The characterization of the prostheses was achieved using a set of variables split into four categories, including temporal characteristics, maximum loading, loading slopes, and impulse. Approximately 360 gait cycles were analyzed for each prosthesis. PRO1 showed a cadence improved by $19 \%$ and $7 \%$, a maximum force on the long axis reduced by $11 \%$ and $19 \%$, and an impulse reduced by $32 \%$ and $15 \%$ during descent of incline and stairs compared with PRO2, respectively. This work confirmed that the proposed apparatus and characterization can reveal how changes of prosthetic components are translated into inner-prosthetic loading.
\end{abstract}

Key words: activity of daily living, artificial limb, boneanchorage, gait, impulse, loading, osseointegration, prosthetic knee unit, temporal characteristics, transfemoral amputation.

\section{INTRODUCTION}

Individuals with transfemoral amputation (TFA) are normally supplied with socket-suspended prostheses. Some of the issues associated with the interface between the residuum and the socket can be resolved with a boneanchored prosthesis [1]. In this case, the prosthesis is attached to the residuum using an implant inserted into the bone [1-3]. To date, approximately 300 individuals

\footnotetext{
Abbreviations: ADL $=$ activity of daily living, $\mathrm{AP}=$ anteroposterior, $\mathrm{BW}=$ body weight, $\% \mathrm{BW}=$ percent of body weight, $\% \mathrm{BWm}=$ moment of percent of body weight, $\mathrm{F}=$ force, $\mathrm{GC}=$ gait cycle, \%GC = percent of gait cycle, $\mathrm{IN}-\mathrm{A}=$ ascending incline, IN-D = descending incline, $\mathrm{LG}=$ long, $\mathrm{M}=$ moment, $\mathrm{ML}=$ mediolateral, $\mathrm{PRO} 1=$ prosthesis 1 (mechanical), $\mathrm{PRO} 2=$ prosthesis 2 (microprocessor-controlled), ST-A = ascending stairs, ST-D = descending stairs, TFA = transfemoral amputation, WA-L = walking on long walkway, WA-S = walking on short walkway.

*Address all correspondence to Laurent Frossard, PhD; Department of Kinesiology, Université du Québec à Montréal, C.P. 2222, Succursale, Centre-Ville, Montréal, Québec, H3C $3 P 8$ Canada; 514-987-3000, ext 3704; fax 514987-6616. Email: laurentfrossard@yahoo.com.au

http://dx.doi.org/10.1682/JRRD.2012.04.0062
} 
with this kind of attachment using either the ITAP (Stanmore Implants; Elstree, United Kingdom) [4]; EFFT, now sold as the Integral Leg Prosthesis (Orthodynamics Pty Ltd; Gloucestershire, United Kingdom) [5]; or OPRA (Integrum AB; Mölndal, Sweden) [6] systems. This technique can contribute to a significant improvement in quality of life [7] despite the length of treatment [8], sporadic fractures of implant parts following a fall [9-11], and occasional infections [7,11-12]. Some of these problems are believed to be somehow associated with the prosthetic components fitted during restricted and unrestricted loading.

\section{Selection of Components for Bone-Anchored Transfemoral Prosthesis}

Currently, the selection of knee and ankle units is based on clinical experience and depends mainly on manufacturer's instructions, strength of the bone anchorage, lifestyle, and cost. Although there are variations, choice of knee is often determined around the following options. A polycentric knee could suit during initial restricted prosthetic loading because the application of partial body weight (BW) loading is enough to secure stance-phase stability of the knee mechanism. A microprocessorcontrolled knee could be used in a more definitive prosthesis, during unrestricted loading, because it requires applying the full BW. Also, it can accommodate an active lifestyle while potentially reducing the risk of falls [13].

Clearly, these choices are critical in the development of rehabilitation programs as well as the design and management of fixation parts (e.g., load limits, strength of implant parts, threshold of protective device) $[1,6,11,14]$. However, to date, little information exists on the effect of prostheses on the load applied on the fixation to back up these fitting options.

Some of this information can be gained through a characterization of the prosthesis, defined as a process of assessing the inner-prosthetic loading profile of an ensemble of components during actual prosthesis use, including not only typical clinical observations (e.g., fitting, alignment), but more importantly, activities of daily living (ADLs).

\section{Conventional Characterization of Prosthesis}

Typically, such characterization relies on kinetic data for ankle, knee, and hip of nondisabled and prosthetic limbs [15-24] "to evaluate how loads are transmitted through the prosthesis" [25, p. 206]. This load can be calculated using inverse dynamics equations requiring kinematic data captured by a motion analysis system and ground reaction forces measured by force plates [26-27].

Some of the most important shortcomings of this method are inherent to the experimental setting of these instruments [27]. In particular, instrumentation of stairs and inclines with floor-mounted force plates is possible but tedious and often leads to assessments that could only be somewhat ecological. Marginal calculation errors caused by location of center of pressure and joint center through external markers could be increasingly propagated upward between the ankle, knee, and hip [28-30]. Finally, data processing is often time-consuming and labor-intensive. Consequently, this method can only partially accommodate the clinical expectations for an ecological assessment of the inner-prosthetic loading.

\section{Characterization Based on Direct Kinetic Measurements}

Alternatively, a prosthesis could be characterized using load sensors embedded between components. Recently, portable kinetic systems based on a multi-axial transducer connected to a recording device were used to measure the load applied on the residuum of individuals with lower-limb amputation [31-32]. To date, studies of the load applied on the osseointegrated fixation of TFAs focused only on the effects of load-bearing exercises [8], walking aids [33], walking [34], standardized ADLs [35], ADLs in open environment [36-37], and falls [9-10]. All combined, more ecological information was provided, demonstrating that this alternative approach is relevant and practical to clinicians. Furthermore, these studies, particularly the ones examining locomotion [33-35], give some preliminary information demonstrating the potential benefits of this approach to characterize boneanchored prostheses.

These studies provided key practical cues about the transducer included in the portable kinetic systems (e.g., mounting, orientation, calibration). More importantly, they demonstrated that these systems are capable of directly measuring the three components of force $(F)$ and moment (M) without calculations and for a large number of gait cycles (GCs), in contrast with inverse dynamics. Furthermore, these studies described a set of standardized ADLs including, but not limited to, the ones usually considered to assess prosthetic components (e.g., straightlevel walking, ascending stairs [ST-A], descending stairs 
[ST-D], ascending incline [IN-A], and descending incline [IN-D]) [13,34-35,38-40]. Finally, these studies laid out some basic ways to extract gait temporal variables, peaks and local extremas, and impulse from inner-prosthetic loading data.

\section{Need for More Evidence}

Nonetheless, more evidence is required to evaluate to what extent the apparatus, protocols, and analyses previously presented are actually suitable to characterize bone-anchored prostheses. Indeed, a need exists for a pilot study replicating typical data collection and, eventually, exploring further possible analyses in the view of differentiating loading between prostheses.

\section{Aim, Purpose, and Objectives}

The ultimate aim of this study was to contribute to an evidence-based prescription of prosthetic components for individuals with TFA fitted with bone-anchored prostheses. The purpose of this pilot study was to propose a characterization of prostheses from collection to analysis of inner-prosthetic loading data. The specific objectives were-

1. To directly record forces and moments applied on the three axes of the fixation during six standardized ADLs, including walking on a short walkway (WA-S), ST-D, and IN-D, commonly considered when assessing prosthetic components, as well as walking on a long walkway (WA-L), ST-A, and IN-A.

2. To analyze and interpret the load applied on the fixation using a set of variables split into four categories, including temporal characteristics, maximum loading, and impulse routinely used in previous studies, as well as loading slopes newly presented here.

3. To provide an example of characterization and comparison of two bone-anchored prostheses of an individual with unilateral TFA fitted with an OPRA fixation, including a mechanical (Total Knee, Össur; Reykjavik, Iceland) and microprocessor-controlled (C-Leg, Otto Bock; Vienna, Austria) knee unit.

\section{METHODS}

\section{Participant}

One male (41 yr old, $1.77 \mathrm{~m}, 96.55 \mathrm{~kg}$ ) with unilateral TFA due to trauma participated in this study. The initial amputation and the completion of osseointegration treatment took place 14 and 8 yr before this study, respectively. The participant was fully rehabilitated and active with an overall functional level corresponding to K4, indicating a fairly high ambulatory capacity according to Medicare Functional Classification Level.

\section{Apparatus}

The load applied on the fixation was measured while the participant used two different prostheses, mechanical (PRO1) and microprocessor-controlled (PRO2) (Figure 1). Both prostheses included a connector, four-hole standard adapter and designed plate, and transducer. The participant used the connector to attach each prosthesis to the fixation.

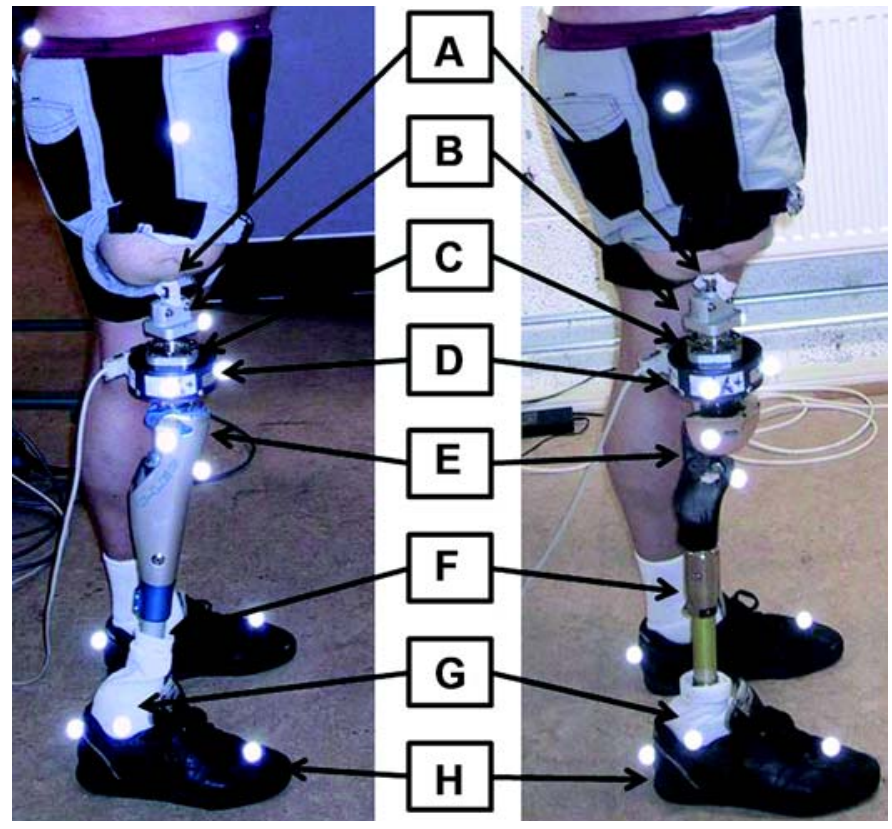

Figure 1.

Two prostheses used to measure load applied to (a) boneanchored fixation of individual with transfemoral amputation, including (b) connector, (c) 4-hole standard adapter and designed plate, (d) transducer (model 45E15A, JR3 Inc), (e) knee joint, (g) foot, and (h) footwear. Mechanical prosthesis on left includes (e) C-Leg (Otto Bock), (f) tube adapter (Otto Bock), and (g) C-Walk foot (model 1C40, Otto Bock). Microprocessorcontrolled prosthesis on right includes (e) Total Knee (Össur), (f) Total Shock (Össur), and (g) tube adapter (Össur) and Trustep (College Park Inc). 
Table 1.

Overview of prosthetic components, alignment in relation to hip coordinate system, and data collection for two prostheses used during load measurement of activities of daily living.

\begin{tabular}{llc}
\hline Prosthetic Components & Prosthesis 1 & Prosthesis 2 \\
\hline Type & Model 45E15A $^{*}$ & Model 45E15A $^{*}$ \\
Transducer & C-Leg $^{\dagger}$ & Total Knee $^{\ddagger}$ \\
Knee Joint & - & Total Shock $^{\ddagger}$ \\
Protective Device Below Knee & C-Walk foot & Trustep $^{\dagger}$ \\
Ankle Joint and Foot & & 3.70 \\
Mass (kg) & 3.98 & 2.30 \\
Prosthesis & 2.45 & \\
Below Transducer & & \\
\hline
\end{tabular}

\begin{tabular}{|c|c|c|c|c|}
\hline \multirow{2}{*}{$\begin{array}{l}\text { Alignment in Relation to } \\
\text { Hip Coordinate System }\end{array}$} & \multicolumn{2}{|c|}{ Prosthesis 1} & \multicolumn{2}{|c|}{ Prosthesis 2} \\
\hline & Position (cm) & Orientation & Position (cm) & Orientation \\
\hline \multicolumn{5}{|l|}{ Center of Transducer } \\
\hline Anteroposterior Axis & -0.02 & Anterior & -0.02 & Anterior \\
\hline Long Axis & -31.91 & Inferior & -34.17 & Inferior \\
\hline \multicolumn{5}{|l|}{ Center of Prosthetic Knee Joint } \\
\hline Anteroposterior Axis & -0.18 & Anterior & 1.54 & Posterior \\
\hline Long Axis & -38.63 & Inferior & -41.30 & Inferior \\
\hline \multicolumn{5}{|l|}{ Center of Prosthetic Ankle Joint } \\
\hline Anteroposterior Axis & 3.47 & Posterior & 9.64 & Posterior \\
\hline Medioateral Axis & -8.89 & Medial & -11.00 & Medial \\
\hline Long Axis & -79.15 & Inferior & -80.46 & Inferior \\
\hline Ascending Stairs & 5 & 45 & 5 & 46 \\
\hline Descending Stairs & 5 & 27 & 5 & 56 \\
\hline Ascending Incline & 6 & 66 & 6 & 62 \\
\hline Descending Incline & 6 & 71 & 6 & 77 \\
\hline $\begin{array}{l}{ }^{*} \text { JR3 Inc; Woodland, California. } \\
\text { †Otto Bock; Vienna, Austria. } \\
\text { ‡ Össur; Reykjavik, Iceland. } \\
\text { § College Park Inc; Warren, Michigan }\end{array}$ & & & & \\
\hline
\end{tabular}

As detailed in Table 1, PRO1 included a C-Leg, tube adapter (Otto Bock), C-Walk foot (model 1C40, Otto Bock), and hard running shoe. PRO2 included a Total Knee, Total Shock (Össur), tube adapter (Össur), Trustep (College Park Inc; Warren, Michigan), and same hard running shoe. PRO1 and PRO2 were purposely assembled with unique knee and ankle joint combinations in order to assess the loading effect of the whole prosthesis as it is usually worn by the participant. This is in contrast with typical studies assessing a particular component (e.g., microprocessor-controlled knee), which tend to fit the rest of the prosthesis with the same components (e.g., sockets, ankles, feet, footwear) to reduce confounding effects.
A prosthetist with over $15 \mathrm{yr}$ of experience, including several years working with bone-anchored prostheses, handled all aspects of prosthesis fitting. The prosthetist replicated the alignment of each prosthesis as closely as possible to the participant's original alignment. The connector and transducer replaced the device usually fitted, including a fail-safe mechanism [6]. Both knees were dropped by approximately $2.5 \mathrm{~cm}$ compared with the usual alignment to provide sufficient space to mount the transducer. Table 1 shows positions and orientations of each component in relation to the three axes of the hip coordinate system. The difference in position for each component was $<2.11$ and $2.75 \mathrm{~cm}$ on the mediolateral 
(ML) and long (LG) axes, respectively. The difference on the anteroposterior (AP) axis was nil for the transducer as well as 1.72 and $6.16 \mathrm{~cm}$ for the knee and ankle joints, respectively. These differences were due to a smaller knee flexion angle of the C-Leg in the upright standing position.

The load was measured and recorded at $200 \mathrm{~Hz}$ using a multi-axial transducer and a laptop computer [810,28,32-36,41]. The three components of forces and moments were measured with accuracy better than $1 \mathrm{~N}$ and $1 \mathrm{Nm}$, respectively. The prosthetist mounted the transducer between the fixation and the prosthetic knee and aligned it so that its vertical axis was co-axial with the LG axis of the fixation. The other axes corresponded to the anatomical AP and ML direction of the fixation.

\section{Recording}

The load was recorded during two sessions, starting with PRO1 in the morning and followed by PRO2 in the afternoon, after a long rest. Each session occurred according to protocol previously published [32,34-35], including the following key steps.

First, the prosthetist set up and aligned the prosthesis, including the transducer. Acclimation time was limited because the participant was familiar with both prostheses. PRO2 was his first prosthesis after amputation and following osseointegration treatment, which he wore for several years. PRO1 has been his current daily prosthesis for several months. Approximately $15 \mathrm{~min}$ of practice was allowed before recording to ensure participant confidence, safety, and comfort.

Second, the participant was asked to perform six standardized ADLs regularly performed [42-43] that are likely to generate some of the highest loads. WA-S (5 m long), ST-D with 11 steps (30 $\mathrm{cm}$ high and $34 \mathrm{~cm}$ deep), and $6.5^{\circ}$ IN-D (30 m long) are activities commonly considered when assessing prosthetic components [38]. However, WA-L (20 m long), ST-A, and IN-A were also recorded to provide more comprehensive characterization, and eventually, to establish ground levels for future considerations. At first glance, the two walking activities might appear redundant. WA-S is usually assessed in gait laboratory settings. A WA-L was included to measure a higher number of steps. Ecological assessments were ensured by instructing the participant to complete each activity at a self-selected comfortable pace, to use the stair handrail if needed, and to take sufficient rest between trials to avoid fatigue. Table 1 provides the number of trials recorded for each activity.
Finally, the prosthesis was removed to allow bench top measurement of the inertial characteristics for the calibration (i.e., zero-offset).

\section{Processing}

The raw data for each trial was imported into a customized MATLAB software program (MathWorks Inc; Natick, Massachusetts), implementing the following data processing steps [32,34-35]:

- Application of a calibration matrix to eliminate crosstalk and to correct the offset of electrical zero.

- Selection of relevant segment of data to eliminate GCs corresponding with gait initiation and termination.

- Identification of heel contact and toe-off for each selected GC using the curve of the force on the LG axis of the fixation $\left(\mathrm{F}_{\mathrm{LG}}\right)$.

- Detection of maximal loading as well as the beginning and the end points of the regression line for each slope.

- Normalization from 0 to 100 of the curves of forces and moments of each GC to facilitate averaging of trials and reporting of events in percent of GC (\%GC).

\section{Characterization}

The characterization of each prosthesis relied on 32 loading variables split into four categories, corresponding with temporal characteristics, maximum loading, and impulse, as described previously, as well as with loading slopes:

- Temporal characteristics of the prosthetic leg, including the cadence in strides per minute for a given trial as well as the duration of each GC in seconds, and the duration of support and swing in \%GC [44]. The characteristics are surrogate measurements of the functional outcomes [36-37].

- Maximum loading, described by the onset in \%GC and magnitude of the maximal force in percent of BW (\%BW) and moment in \%BW (\%BWm) along the three axes of the fixation [34-35]. This information is necessary to determine the loading limits of components.

- Impulse of the norm and the three components of forces in Newtons, determined using the trapeze method. The overall impulse was used as a clinical indicator reflecting the loading regimen [8,33-35] that is useful to determine prosthesis usage and to estimate components fatigue.

- Loading slopes of the forces and moments along the three axes during initial and terminal loading phases. 
A slope was represented by the angle in degrees between the time and the regression line that passed by a flat segment of a loading curve selected manually. The algebraic congruence was obtained between the time in seconds, the forces in Newtons, and the moments in Newton meters through rescaling by a factor 1,000 and 10 [9]. Small and large magnitudes corresponded to flat and steep slopes, while positive and negative values indicated upward and downward inclinations, respectively. Emphasis was placed on the slopes occurring during the first and last sections of the support because both phases are mainly concerned with safety (e.g., buckling of knee mechanism) and propulsion (e.g., forward push). The slopes reflect the loading pattern using a single value combining nonnormalized time and load magnitude.

\section{Comparative Analysis}

All GC data was collated to determine mean \pm 1 standard deviation, as detailed in Table 1. The difference between prostheses was determined with PRO2 - PRO1. Therefore, a positive and negative difference between a variable indicated that $\mathrm{PRO} 2$ is algebraically larger or smaller than PRO1, respectively. A simple two-sided $t$ test with $p$-values considering differences was deemed significant at $p<0.05$ acceptable for this pilot study relying on a single case.

Comparison of both prostheses relied on the count of the maximum absolute difference and its corresponding activity and the number of positive and negative differences that were not statistically significant as well as significantly different.

\section{RESULTS}

A total of 727 GCs were analyzed, including 363 for PRO1 and 364 for PRO2 (Table 1). Figures 2, 3, and 4 provide an overview of the forces and moments applied on the three axes of the residuum during walking, stairs, and incline activities. The participant used the handrail with his opposite hand. Moreover, the participant climbed one stair per step for the three first trials and two stairs per steps for three last trials. ST-D was performed "step over step" with PRO1 and "one at a time” with PRO2.

\section{Temporal Characteristics}

As presented in Table 2, the difference was negative and positive for all activities for the cadence and duration of GC, respectively. The difference was negative and positive for two and four activities for the duration of support, respectively. The difference was significantly different for 21 (88\%) of the 24 possible comparisons of temporal characteristics.

\section{Maximum Loading}

As presented in Table 3, the maximum absolute differences were $30.19 \% \mathrm{BW}$ for $\mathrm{F}_{\mathrm{AP}}, 0.35 \% \mathrm{BWm}$ for $\mathrm{M}_{\mathrm{AP}}$, and $0.72 \% \mathrm{BWm}$ for $\mathrm{M}_{\mathrm{LG}}$ during IN-D, as well as 15.28 \%BW for $\mathrm{F}_{\mathrm{LG}}$ during ST-D, $4.69 \% \mathrm{BWm}$ for $\mathrm{M}_{\mathrm{ML}}$ during IN-A, and $2.39 \% \mathrm{BW}$ for $\mathrm{F}_{\mathrm{ML}}$ during WA-S. The difference was positive for all activities for $F_{A P}, F_{M L}$, $\mathrm{F}_{\mathrm{LG}}$, and $\mathrm{M}_{\mathrm{ML}}$. The number of activities presenting positive and negative differences was five and one for $\mathrm{M}_{\mathrm{AP}}$ and four and two for $\mathrm{M}_{\mathrm{LG}}$, respectively. The difference was significantly different for 30 (83\%) and 34 (94\%) of the 36 possible comparisons of onset and magnitude of the maximal load, respectively.

\section{Loading Slope}

All the slopes occurred within the first 57, 41, 34, 24, 55, and $48 \%$ GC during initial loading and between 12 and $72 \% G C, 31$ and $70 \% G C, 24$ and $71 \% G C, 15$ and $80 \% \mathrm{GC}, 14$ and $82 \% \mathrm{GC}$, and 33 and $93 \% \mathrm{GC}$ during terminal loading for $F_{A P}, F_{M L}, F_{L G}, M_{A P}, M_{M L}$, and $\mathrm{M}_{\mathrm{LG}}$, respectively.

As presented in Table 4, during initial loading, the difference was positive for all activities for $F_{A P}, M_{M L}$, and $\mathrm{M}_{\mathrm{LG}}$. The number of activities presenting positive and negative differences was three for $\mathrm{F}_{\mathrm{ML}}$ and $\mathrm{F}_{\mathrm{LG}}$ and four and two for $\mathrm{M}_{\mathrm{AP}}$, respectively. During terminal loading, the difference was negative for all activities for $\mathrm{F}_{\mathrm{AP}}$ and $\mathrm{M}_{\mathrm{ML}}$. The number of positive and negative differences was three and three for $\mathrm{F}_{\mathrm{ML}}$, two and four for $\mathrm{F}_{\mathrm{LG}}$ and $\mathrm{M}_{\mathrm{AP}}$, and five and one for $\mathrm{M}_{\mathrm{LG}}$, respectively. The difference was significantly different for 27 (75\%) and 33 (92\%) of the 36 possible comparisons of slope occurring during initial and terminal loading, respectively.

\section{Impulse}

As presented in Table 5, the difference of impulse was positive for all activities on the ML and LG axes. It was positive and negative for four and two activities on the AP axis, respectively. The difference of overall 


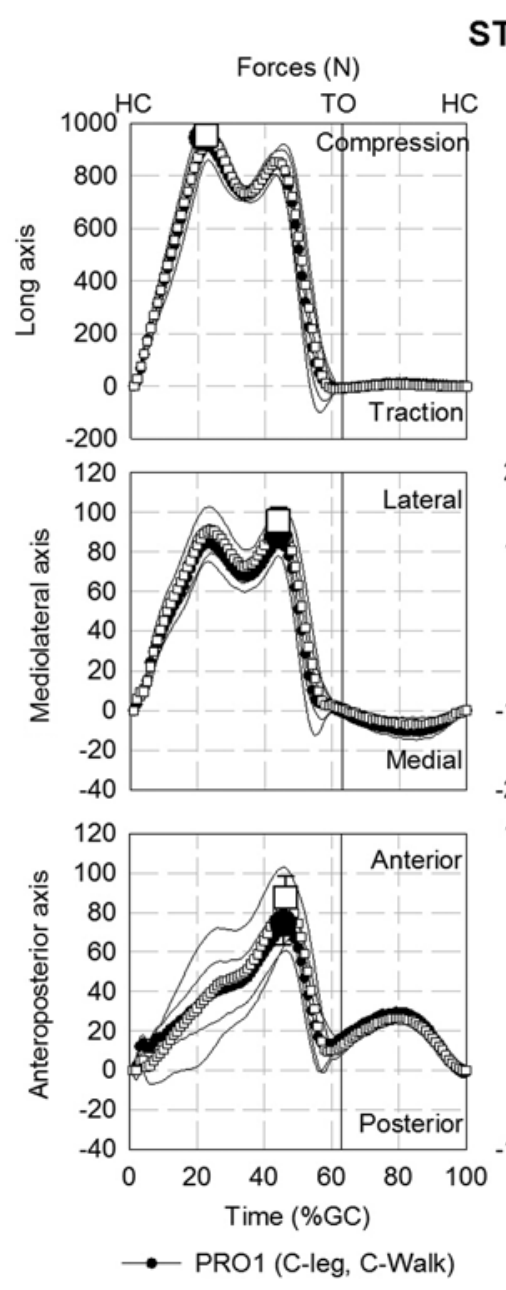

ST-A
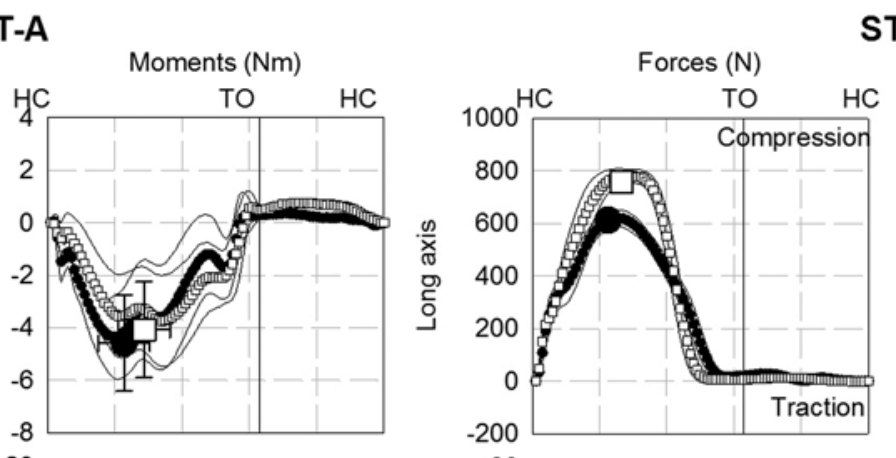

ST-D
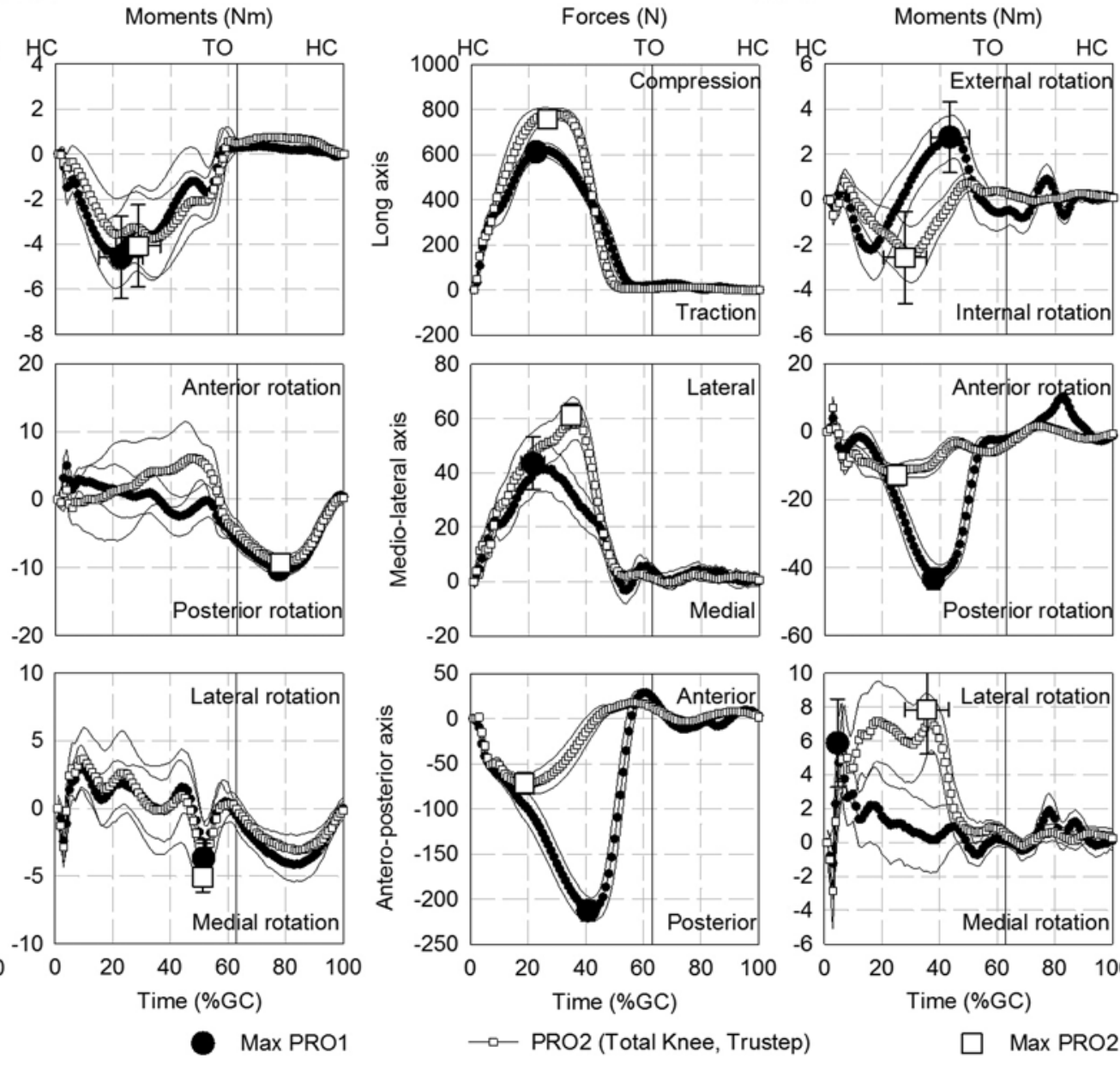

Figure 2.

Maximum value (max) as well as mean \pm 1 standard deviation of forces and moments applied over percent of gait cycle (\%GC) along anteroposterior, mediolateral, and long axes of residuum during stair ascent (ST-A) and descent (ST-D). HC = mean heel contact, $\mathrm{PRO} 1=$ prosthesis 1 (mechanical), $\mathrm{PRO} 2=$ prosthesis 2 (microprocessor-controlled), TO = mean toe-off.

impulse was positive for all activities. All 24 possible comparisons of impulse were statistically significant.

\section{DISCUSSION}

\section{Characterization of Prosthesis}

The primary contribution of this work was to demonstrate that the proposed characterization (e.g., apparatus, protocol, analysis) can describe how changes in prostheses are translated into loading on the fixation. In addition, this study highlights a limit of the maximum-to-maximum comparison, mainly due to the lack of systematic onset concordance of algebraic maximum loading between patterns. Therefore, complementary analysis of the loading slopes and, eventually, a peak-to-peak comparison are needed. For example, the comparison of maximum of $\mathrm{M}_{\mathrm{ML}}$ during IN-D corresponding to $-6.05 \pm$ $0.24 \%$ BWm for PRO1 and $-1.95 \pm 0.50 \%$ BWm for PRO2 (Table 3) can be misleading since the terminal slope occurring between $46 \% \mathrm{GC}$ and $59 \% \mathrm{GC}$ was $88.42^{\circ} \pm 0.19^{\circ}$ with PRO1 and $-87.97^{\circ} \pm 1.36^{\circ}$ with PRO2, respectively (Table 4).

Furthermore, this study reports mixed evidence supporting a systematic inclusion of ascent activities in prostheses characterization. Differences between both prostheses during ST-A and IN-A were negligible for $\mathrm{F}_{\mathrm{LG}}$ but more significant for the norm of impulse, as 


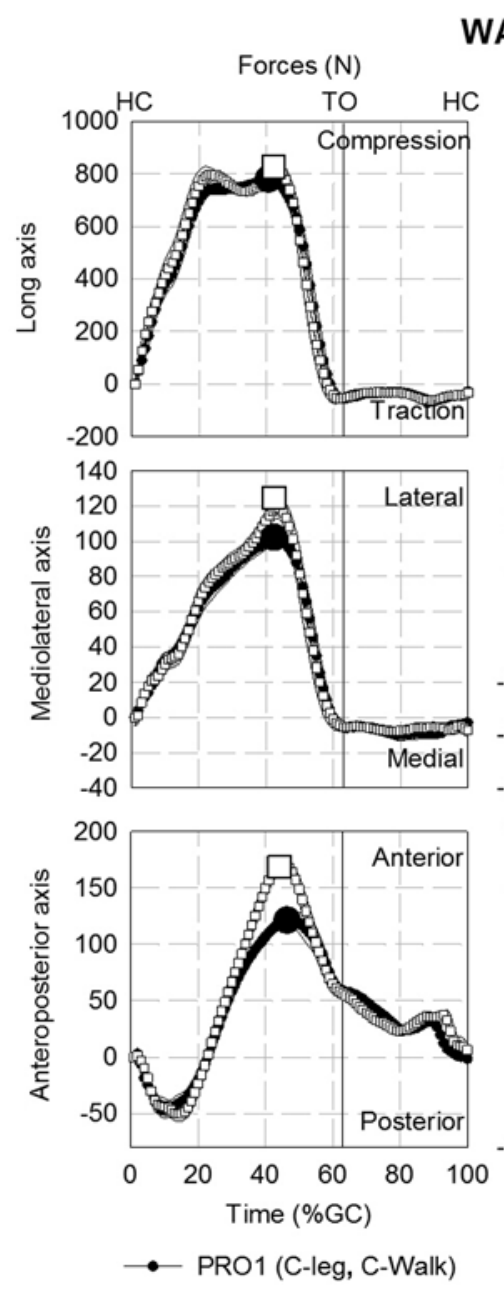

WA-L
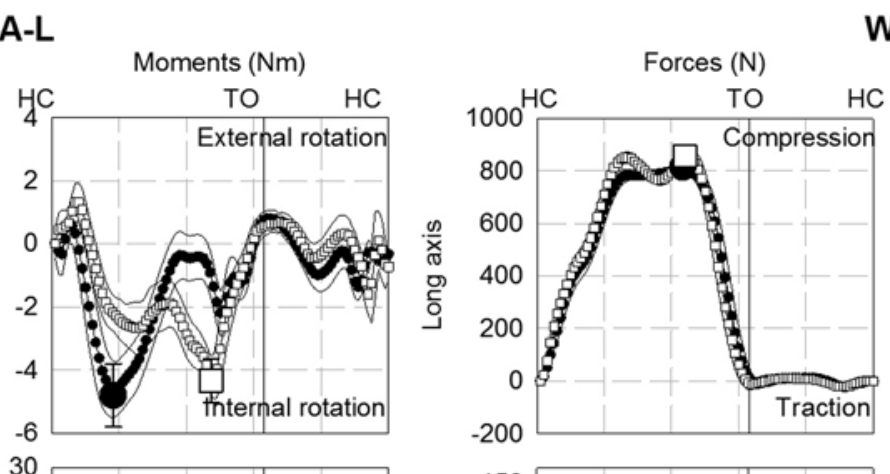

WA-S
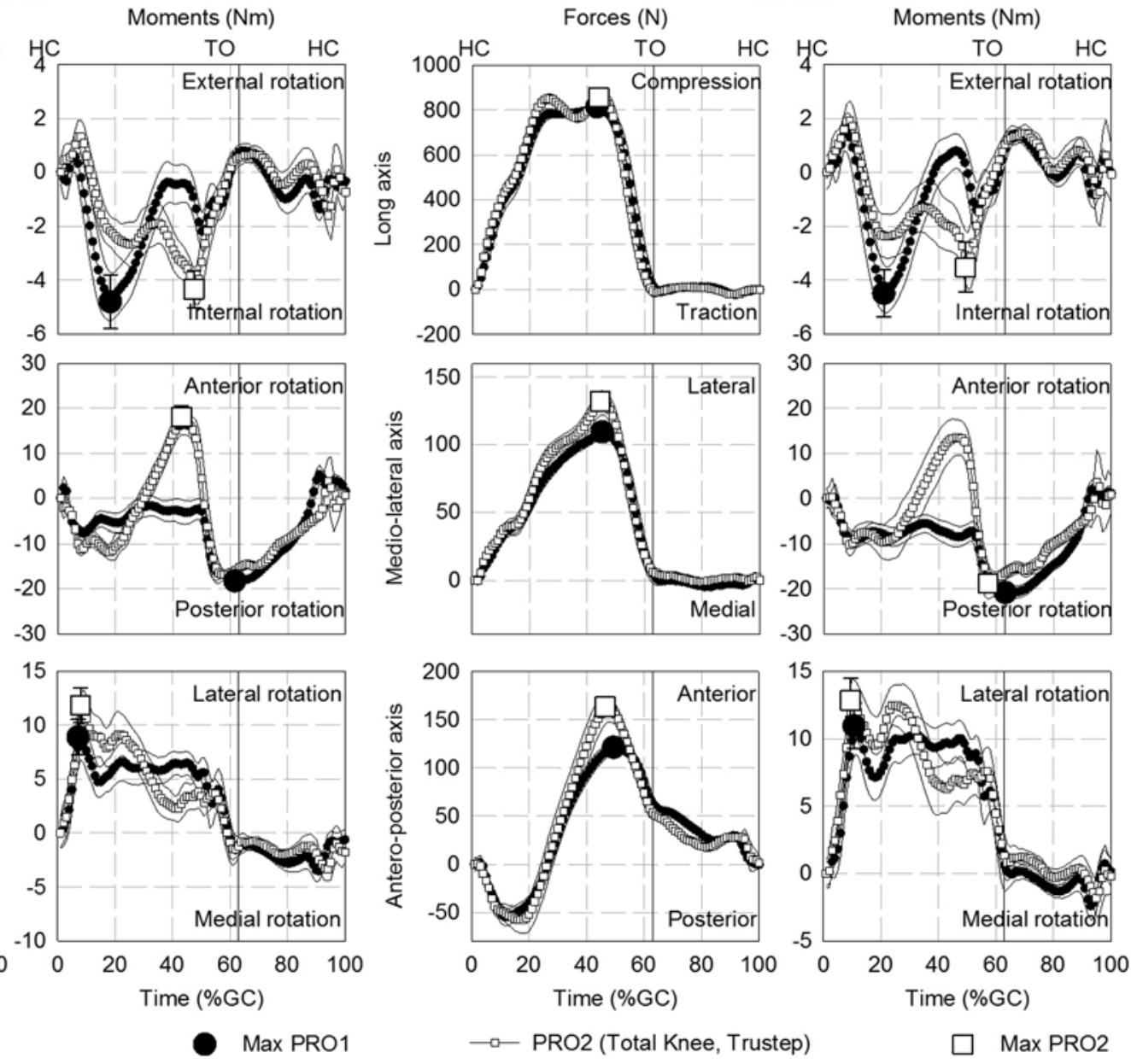

$\longrightarrow$ - PRO2 (Total Knee, Trustep)

Max PRO2

Figure 3.

Maximum value (max) as well as mean \pm 1 standard deviation of forces and moments applied over percent of gait cycle (\%GC) along anteroposterior, mediolateral, and long axes of residuum during walking in long (WA-L) and short (WA-S) walkway. HC = mean heel contact, $\mathrm{PRO} 1=$ prosthesis 1 (mechanical), $\mathrm{PRO} 2=$ prosthesis 2 (microprocessor-controlled), TO = mean toe-off.

detailed later. This suggests that prosthesis characteristics might have little effect on these activities and support previous studies discarding them [38]. Nonetheless, loading patterns and maximum magnitudes must be known for all activities to provide benchmark data for predictive models of prosthesis usage during ADLs (e.g., activities pattern recognition, fatigue prediction, finite elements models [45-46]).

Also, the succinct comparison between WA-S and WA-L reveals significant differences in most loading variables. This provides ground to hypothesize that assessments in experimental and real-world conditions might differ. Further investigations will be required to substantiate these findings.

Finally, this pilot study demonstrated the capacity of the proposed characterization to address the issues of under- or over-prescription of prosthetic components, corresponding to the disagreement between the functional capacity of the individual and the performance of the components [47-48]. For instance, this characterization can contribute to matching the walking abilities of individuals with TFA fitted with a fixation or a conventional socket with a relevant prosthetic knee unit, particularly those classified as limited community ambulators (e.g., Medicare Functional Classification Level 2) [42,49]. 


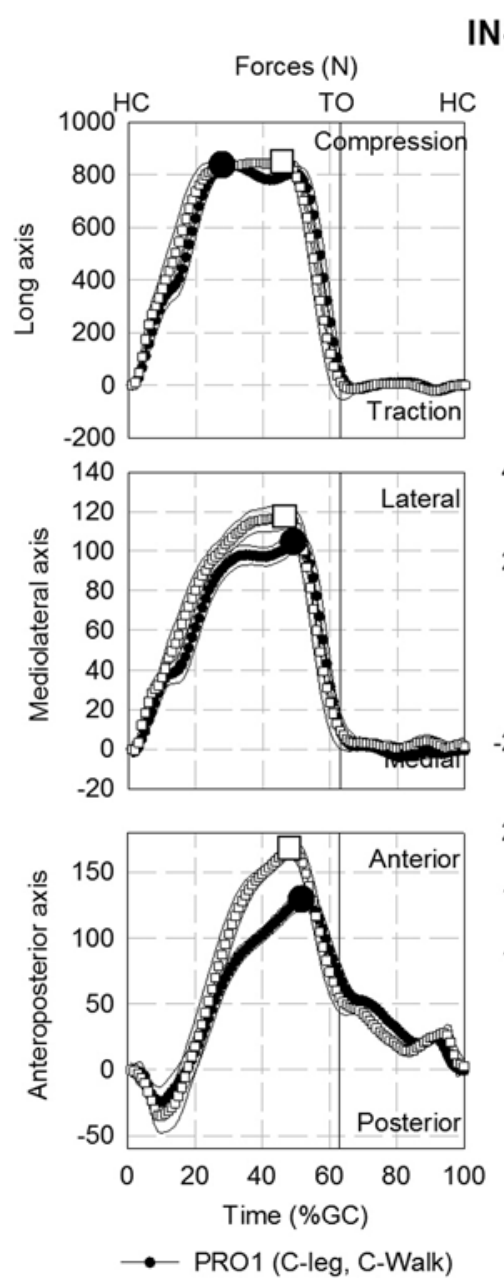

IN-A
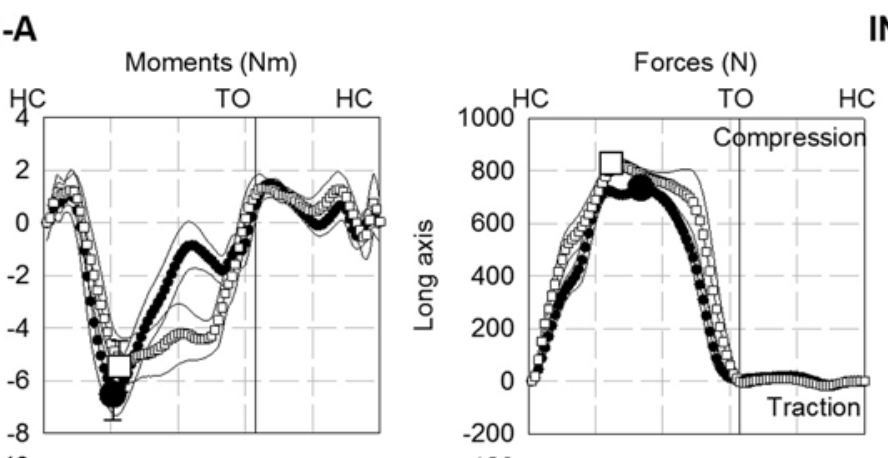

IN-D
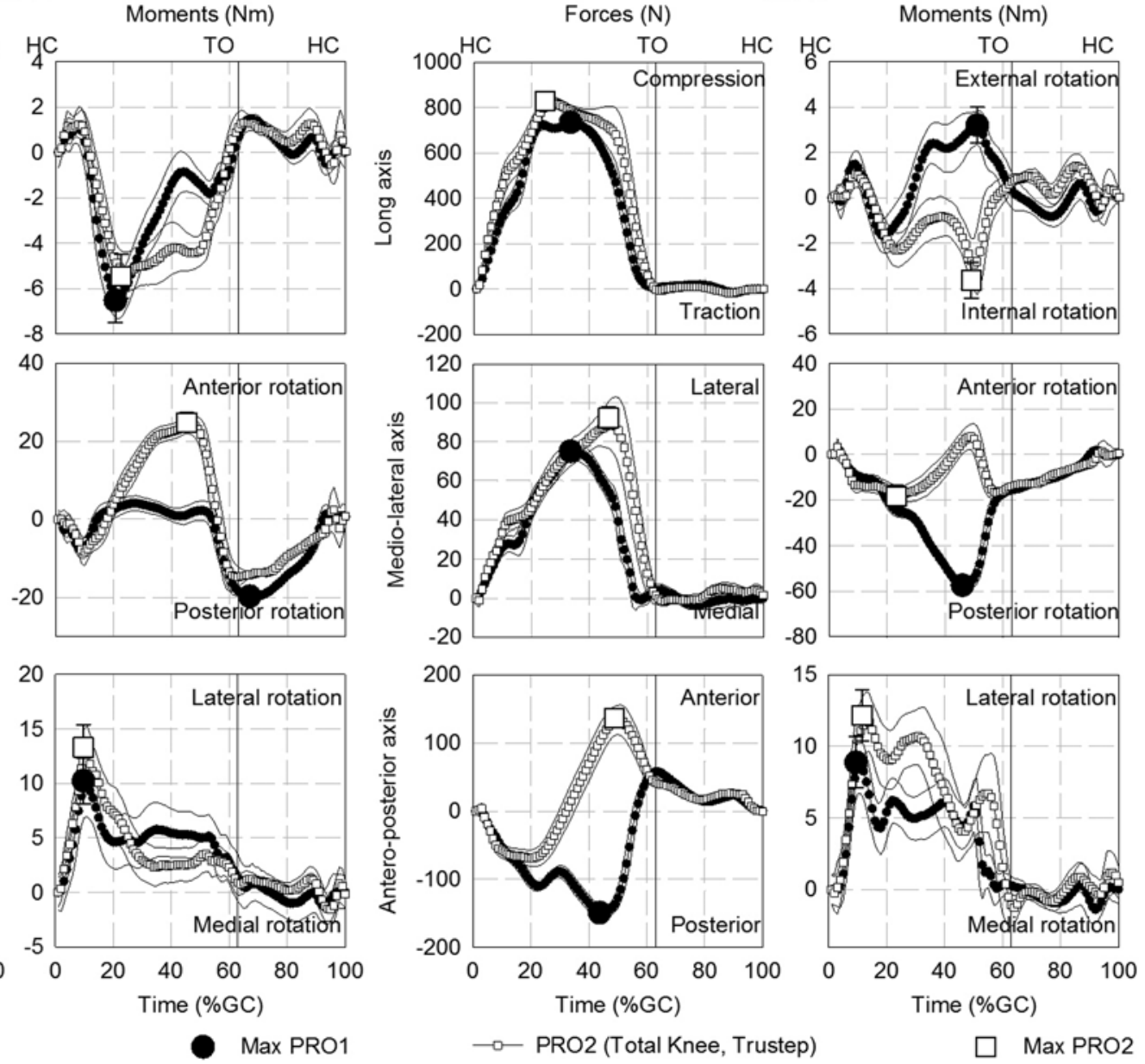

Figure 4.

Maximum value (max) as well as mean \pm 1 standard deviation of forces and moments applied over percent of gait cycle (\%GC) along anteroposterior, mediolateral, and long axes of residuum during incline ascent (IN-A) and descent (IN-D). HC = mean heel contact, $\mathrm{PRO} 1$ = prosthesis 1 (mechanical), $\mathrm{PRO} 2=$ prosthesis 2 (microprocessor-controlled), $\mathrm{TO}=$ mean toe-off.

\section{Prostheses Comparison}

The secondary contributions of this study are associated with the actual results of the comparison between two prostheses for this participant. The results showed that cadence, duration of GC, and support-to-swing ratio for all activities with both prostheses were among the best when compared with similar populations using socket-suspended prostheses [36,44]. Prosthetic benefits of the osseointegration fixation were translated into high functional outcomes for this participant [6-7,12,44].

Furthermore, the performances in some key variables appear favorable to PRO1 compared with PRO2. Despite being approximately $0.28 \mathrm{~kg}$ heavier, PRO1 showed-
- Cadence significantly improved by 19, 8, 7, and 4 percent during IN-D, IN-A, ST-D, and WA-S, respectively.

- Maximum $\mathrm{F}_{\mathrm{LG}}$ consistently reduced by 19, 11, 6, 5, 1, and 1 percent during ST-D, IN-D, WA-L, WA-S, INA, and ST-A, respectively.

- Overall impulse consistently reduced by 32, 15, 10, 9, 7, and 6 percent during IN-D, ST-D, IN-A, WA-L, STA, and WA-S, respectively.

Some of these differences appear small when observed over one GC. However, they can become increasingly important when cumulated over a large number of GCs [36-37].

By definition, the load measured by the transducer reflects the interaction between the body segments (e.g., 
JRRD, Volume 50, Number 5, 2013

Table 2.

Mean \pm 1 standard deviation and differences of temporal characteristics with both prostheses during activities of daily living.

\begin{tabular}{|c|c|c|c|c|}
\hline \multirow{2}{*}{ Prosthesis } & \multirow{2}{*}{$\begin{array}{c}\text { Cadence } \\
\text { (strides/min) }\end{array}$} & \multicolumn{3}{|c|}{ Duration } \\
\hline & & Cycle (s) & Support (\%GC) & Swing (\%GC) \\
\hline \multicolumn{5}{|l|}{$\overline{\text { PRO1 }}$} \\
\hline WA-L & $53 \pm 1$ & $1.123 \pm 0.050$ & $59.08 \pm 1.13$ & $40.93 \pm 1.13$ \\
\hline WA-S & $52 \pm 1$ & $1.151 \pm 0.054$ & $63.54 \pm 1.35$ & $36.46 \pm 1.35$ \\
\hline ST-A & $43 \pm 3$ & $1.372 \pm 0.105$ & $55.83 \pm 2.11$ & $44.17 \pm 2.11$ \\
\hline ST-D & $50 \pm 2$ & $1.205 \pm 0.042$ & $54.86 \pm 1.44$ & $45.14 \pm 1.44$ \\
\hline IN-A & $50 \pm 1$ & $1.195 \pm 0.042$ & $65.09 \pm 1.32$ & $34.91 \pm 1.32$ \\
\hline IN-D & $56 \pm 0$ & $1.067 \pm 0.024$ & $59.23 \pm 1.38$ & $40.77 \pm 1.38$ \\
\hline \multicolumn{5}{|l|}{ PRO2 } \\
\hline WA-L & $50 \pm 0$ & $1.189 \pm 0.031$ & $58.18 \pm 1.33$ & $41.82 \pm 1.33$ \\
\hline WA-S & $50 \pm 1$ & $1.200 \pm 0.046$ & $62.77 \pm 1.55$ & $37.23 \pm 1.55$ \\
\hline ST-A & $42 \pm 2$ & $1.424 \pm 0.089$ & $56.17 \pm 2.30$ & $43.83 \pm 2.30$ \\
\hline ST-D & $47 \pm 1$ & $1.277 \pm 0.049$ & $50.26 \pm 1.84$ & $49.74 \pm 1.84$ \\
\hline IN-A & $47 \pm 1$ & $1.286 \pm 0.041$ & $63.86 \pm 1.83$ & $36.14 \pm 1.83$ \\
\hline IN-D & $47 \pm 1$ & $1.269 \pm 0.059$ & $61.77 \pm 2.34$ & $38.23 \pm 2.34$ \\
\hline \multicolumn{5}{|c|}{ Difference (PRO2 - PRO1) } \\
\hline WA-L & $-3^{*}$ & $0.066^{*}$ & $-0.90^{*}$ & $0.90^{*}$ \\
\hline WA-S & $-2^{*}$ & $0.049^{*}$ & $-0.77^{*}$ & $0.77^{*}$ \\
\hline ST-A & -2 & $0.052^{*}$ & 0.33 & -0.33 \\
\hline ST-D & $-3^{*}$ & $0.072^{*}$ & $-4.60^{*}$ & $4.60^{*}$ \\
\hline IN-A & $-4^{*}$ & $0.091^{*}$ & $-1.23^{*}$ & $1.23^{*}$ \\
\hline IN-D & $-9^{*}$ & $0.202^{*}$ & $2.54^{*}$ & $-2.54^{*}$ \\
\hline \multicolumn{5}{|c|}{$\begin{array}{l}\text { Note: PRO1 consisted of C-Leg (Otto Bock; Vienna, Austria), tube adapter (Otto Bock), and C-Walk foot (model 1C40, Otto Bock). PRO2 consisted of Total Knee } \\
\text { (Ö)ssur; Reykjavik, Iceland), Total Shock (Össur), tube adapter (Össur), and Trustep (College Park Inc; Warren, Michigan). } \\
\text { "Significantly different }(p<0.05) \text {. } \\
\text { \%GC = percent of gait cycle, IN-A = ascending incline, IN-D = descending incline, PRO1 = prosthesis } 1 \text { (mechanical), PRO2 = prosthesis } 2 \text { (microprocessor- } \\
\text { controlled), ST-A = ascending stairs, ST-D = descending stairs, WA-L = walking on long walkway, WA-S = walking on short walkway. }\end{array}$} \\
\hline
\end{tabular}

trunk bending, hip range of movement, walking base) and all components of the prosthesis (i.e., fixation, knee, tube, ankle, foot, footwear). However, several studies demonstrated that this interaction tends to be predominantly driven by the prosthetic knee unit [50]. Therefore, differences presented here can be expected to be mostly due to differences between the Total Knee and C-Leg.

Consequently, the results illustrate well the dilemma around the choice of initial and definitive knee unit after osseointegration treatment, as described previously. The Total Knee is lighter and requires only partial weightbearing to ensure locking of the knee mechanism. However, it creates larger loading in a number of ADLs and presents potentially higher risks of falls. In comparison, the C-Leg generates smaller load in several ADLs and presents lower risks of falls [13]. However, it requires applying nearly full BW to control the knee mechanism. In addition, this choice could be complicated by the prescription of walking aids, making the ability to apply full
BW a less critical selection criterion. A previous study demonstrated that the loading is reduced by approximately 2 to 10 percent depending on walking aid [33].

Furthermore, this study gives an example of a potential paradox with the fitting of the microprocessor-controlled knee in a bone-anchored prosthesis. On one hand, these knees tend to minimize fatigue of fixation parts both directly by reducing the actual load regime and indirectly by decreasing the risks of falls [13]. On the other hand, these knees maximize the functional outcome that can possibly lead to an increase in overall number of GCs taken in the real world. This might prevent bone loss around the fixation [51] while accelerating fatigue of fixation parts [36-37]. However, altogether, a microprocessor-controlled knee might provide the best compromise between gain in functional outcomes, promoting bone health, and risks of fracture. 
Table 3.

Mean \pm 1 standard deviation and differences of onset and magnitude of maximum force (F) and moment (M) along anteroposterior (AP), mediolateral (ML), and long (LG) axes of residuum with both prostheses during activities of daily living.

\begin{tabular}{|c|c|c|c|c|c|c|}
\hline \multirow{2}{*}{ Prosthesis } & \multicolumn{6}{|c|}{ Onset } \\
\hline & $F_{\text {AP }}(\% G C)$ & $F_{M L}(\% G C)$ & $F_{L G}(\% G C)$ & $\mathrm{M}_{\mathrm{AP}}(\% \mathrm{GC})$ & $\mathbf{M}_{M L}(\% G C)$ & $\bar{M}_{L G}(\% G C)$ \\
\hline \multicolumn{7}{|l|}{$\overline{\text { PRO1 }}$} \\
\hline WA-L & $46.43 \pm 1.36$ & $42.40 \pm 1.46$ & $40.59 \pm 1.77$ & $7.16 \pm 1.16$ & $61.59 \pm 1.91$ & $18.19 \pm 2.55$ \\
\hline WA-S & $49.40 \pm 1.57$ & $45.30 \pm 1.91$ & $43.36 \pm 2.07$ & $10.69 \pm 1.69$ & $63.20 \pm 2.11$ & $20.84 \pm 2.12$ \\
\hline ST-A & $45.65 \pm 2.56$ & $43.88 \pm 2.44$ & $21.40 \pm 2.11$ & $51.56 \pm 2.19$ & $77.59 \pm 2.26$ & $22.76 \pm 7.69$ \\
\hline ST-D & $40.82 \pm 2.39$ & $21.64 \pm 4.08$ & $22.57 \pm 2.56$ & $4.65 \pm 2.24$ & $37.84 \pm 2.70$ & $43.38 \pm 6.72$ \\
\hline IN-A & $51.65 \pm 1.38$ & $49.07 \pm 1.74$ & $27.78 \pm 1.87$ & $9.75 \pm 1.66$ & $66.99 \pm 1.88$ & $20.60 \pm 2.00$ \\
\hline IN-D & $43.76 \pm 1.43$ & $33.52 \pm 1.66$ & $33.49 \pm 1.83$ & $9.49 \pm 1.21$ & $46.05 \pm 1.53$ & $51.08 \pm 2.50$ \\
\hline \multicolumn{7}{|l|}{ PRO2 } \\
\hline WA-L & $44.20 \pm 1.36$ & $42.38 \pm 1.46$ & $42.11 \pm 1.77$ & $7.97 \pm 1.16$ & $43.05 \pm 2.26$ & $47.26 \pm 1.01$ \\
\hline WA-S & $46.50 \pm 1.57$ & $44.62 \pm 1.91$ & $43.96 \pm 2.07$ & $9.41 \pm 1.69$ & $57.16 \pm 2.11$ & $49.28 \pm 1.85$ \\
\hline ST-A & $46.36 \pm 2.56$ & $44.03 \pm 2.44$ & $22.45 \pm 2.11$ & $51.28 \pm 2.19$ & $78.06 \pm 2.26$ & $28.68 \pm 7.69$ \\
\hline ST-D & $18.68 \pm 2.39$ & $34.82 \pm 2.16$ & $26.46 \pm 2.56$ & $35.63 \pm 7.57$ & $25.20 \pm 2.70$ & $27.90 \pm 7.38$ \\
\hline IN-A & $48.05 \pm 1.38$ & $46.50 \pm 1.74$ & $45.55 \pm 1.51$ & $9.72 \pm 1.66$ & $45.19 \pm 2.25$ & $22.63 \pm 2.00$ \\
\hline IN-D & $48.76 \pm 1.43$ & $46.67 \pm 1.36$ & $24.61 \pm 1.50$ & $11.48 \pm 1.21$ & $23.26 \pm 2.31$ & $49.04 \pm 2.50$ \\
\hline \multicolumn{7}{|c|}{ Difference (PRO2 - PRO1) } \\
\hline WA-L & $-2.24^{*}$ & -0.01 & $1.51^{*}$ & $0.80^{*}$ & $-18.54^{*}$ & $29.07^{*}$ \\
\hline WA-S & $-2.89^{*}$ & $-0.68^{*}$ & $0.60^{*}$ & $-1.28^{*}$ & $-6.04^{*}$ & $28.43^{*}$ \\
\hline ST-A & 0.71 & 0.14 & $1.05^{*}$ & -0.28 & 0.47 & $5.91^{*}$ \\
\hline ST-D & $-22.14^{*}$ & $13.19^{*}$ & $3.90^{*}$ & $30.98^{*}$ & $-12.64^{*}$ & $-15.48^{*}$ \\
\hline IN-A & $-3.61^{*}$ & $-2.57^{*}$ & $17.77^{*}$ & -0.03 & $-21.80^{*}$ & $2.03^{*}$ \\
\hline IN-D & $5.01^{*}$ & $13.15^{*}$ & $-8.88^{*}$ & $2.00^{*}$ & $-22.79^{*}$ & $-2.04^{*}$ \\
\hline \multirow{2}{*}{ Prosthesis } & \multicolumn{6}{|c|}{ Magnitude } \\
\hline & $\overline{F_{A P}(\% B W)}$ & $F_{M L}(\% B W)$ & $F_{L G}(\% B W)$ & $\mathbf{M}_{\mathrm{AP}}(\% \mathrm{BWm})$ & $\mathbf{M}_{\mathrm{ML}}(\% \mathrm{BWm})$ & $\mathbf{M}_{\text {LG }}(\% \mathrm{BWm})$ \\
\hline \multicolumn{7}{|l|}{$\overline{\text { PRO1 }}$} \\
\hline WA-L & $12.82 \pm 0.54$ & $10.79 \pm 0.37$ & $82.28 \pm 2.22$ & $0.94 \pm 0.17$ & $-1.93 \pm 0.10$ & $-0.51 \pm 0.11$ \\
\hline WA-S & $12.81 \pm 0.43$ & $11.54 \pm 0.43$ & $85.89 \pm 1.98$ & $1.16 \pm 0.18$ & $-2.20 \pm 0.15$ & $-0.47 \pm 0.09$ \\
\hline ST-A & $7.87 \pm 1.13$ & $9.35 \pm 0.72$ & $99.65 \pm 3.88$ & $-0.39 \pm 0.11$ & $-1.09 \pm 0.10$ & $-0.48 \pm 0.19$ \\
\hline ST-D & $-22.45 \pm 1.22$ & $4.59 \pm 1.03$ & $64.56 \pm 3.95$ & $0.62 \pm 0.27$ & $-4.56 \pm 0.33$ & $0.29 \pm 0.17$ \\
\hline IN-A & $13.69 \pm 0.68$ & $11.07 \pm 0.50$ & $88.44 \pm 2.28$ & $1.08 \pm 0.22$ & $-2.07 \pm 0.12$ & $-0.69 \pm 0.10$ \\
\hline IN-D & $-15.74 \pm 1.02$ & $7.93 \pm 0.47$ & $77.65 \pm 1.50$ & $0.94 \pm 0.19$ & $-6.05 \pm 0.24$ & $0.34 \pm 0.08$ \\
\hline \multicolumn{7}{|l|}{ PRO2 } \\
\hline WA-L & $17.82 \pm 0.54$ & $13.17 \pm 0.37$ & $87.28 \pm 2.22$ & $1.25 \pm 0.17$ & $1.91 \pm 0.26$ & $-0.46 \pm 0.07$ \\
\hline WA-S & $17.26 \pm 0.43$ & $13.93 \pm 0.43$ & $90.32 \pm 1.98$ & $1.35 \pm 0.18$ & $-1.98 \pm 0.15$ & $-0.37 \pm 0.10$ \\
\hline ST-A & $9.25 \pm 1.13$ & $10.11 \pm 0.72$ & $100.63 \pm 3.88$ & $-0.54 \pm 0.11$ & $-0.98 \pm 0.10$ & $-0.43 \pm 0.19$ \\
\hline ST-D & $-7.55 \pm 1.22$ & $6.45 \pm 0.47$ & $79.85 \pm 3.95$ & $0.83 \pm 0.28$ & $-1.36 \pm 0.33$ & $-0.27 \pm 0.22$ \\
\hline IN-A & $17.77 \pm 0.68$ & $12.41 \pm 0.50$ & $89.67 \pm 2.14$ & $1.40 \pm 0.22$ & $2.62 \pm 0.27$ & $-0.58 \pm 0.10$ \\
\hline IN-D & $14.46 \pm 1.02$ & $9.74 \pm 0.59$ & $87.59 \pm 2.25$ & $1.28 \pm 0.19$ & $-1.95 \pm 0.50$ & $-0.38 \pm 0.08$ \\
\hline \multicolumn{7}{|c|}{ Difference (PRO2 - PRO1) } \\
\hline WA-L & $5.00^{*}$ & $2.38^{*}$ & $4.99^{*}$ & $0.31^{*}$ & $3.83^{*}$ & $0.50^{*}$ \\
\hline WA-S & $4.45^{*}$ & $2.39^{*}$ & $4.43^{*}$ & $0.20^{*}$ & $0.22^{*}$ & $0.10^{*}$ \\
\hline ST-A & $1.38^{*}$ & $0.76^{*}$ & 0.99 & $-0.15^{*}$ & $0.11^{*}$ & 0.05 \\
\hline ST-D & $14.90^{*}$ & $1.86^{*}$ & $15.28^{*}$ & $0.21^{*}$ & $3.21^{*}$ & $-0.56^{*}$ \\
\hline IN-A & $4.07^{*}$ & $1.35^{*}$ & $1.24^{*}$ & $0.32^{*}$ & $4.69^{*}$ & $0.11^{*}$ \\
\hline IN-D & $30.19^{*}$ & $1.81^{*}$ & $9.94^{*}$ & $0.35^{*}$ & $4.10^{*}$ & $-0.72^{*}$ \\
\hline
\end{tabular}

Note: PRO1 consisted of C-Leg (Otto Bock; Vienna, Austria), tube adapter (Otto Bock), and C-Walk foot (model 1C40, Otto Bock). PRO2 consisted of Total Knee (Össur; Reykjavik, Iceland), Total Shock (Össur), tube adapter (Össur), and Trustep (College Park Inc; Warren, Michigan).

${ }^{*}$ Significantly different $(p<0.05)$.

$\% \mathrm{BW}=$ percent of body weight, \%BWm = moment of percent of body weight, \%GC = percent of gait cycle, IN-A = ascending incline, IN-D = descending incline, PRO1 = prosthesis 1 (mechanical), PRO2 = prosthesis 2 (microprocessor-controlled), ST-A = ascending stairs, ST-D = descending stairs, WA-L = walking on long walkway, WA-S = walking on short walkway. 
Table 4.

Mean \pm 1 standard deviation and differences of slope of force (F) and moment (M) along anteroposterior (AP), mediolateral (ML), and long (LG) axes of residuum during initial and terminal loading with both prostheses during activities of daily living.

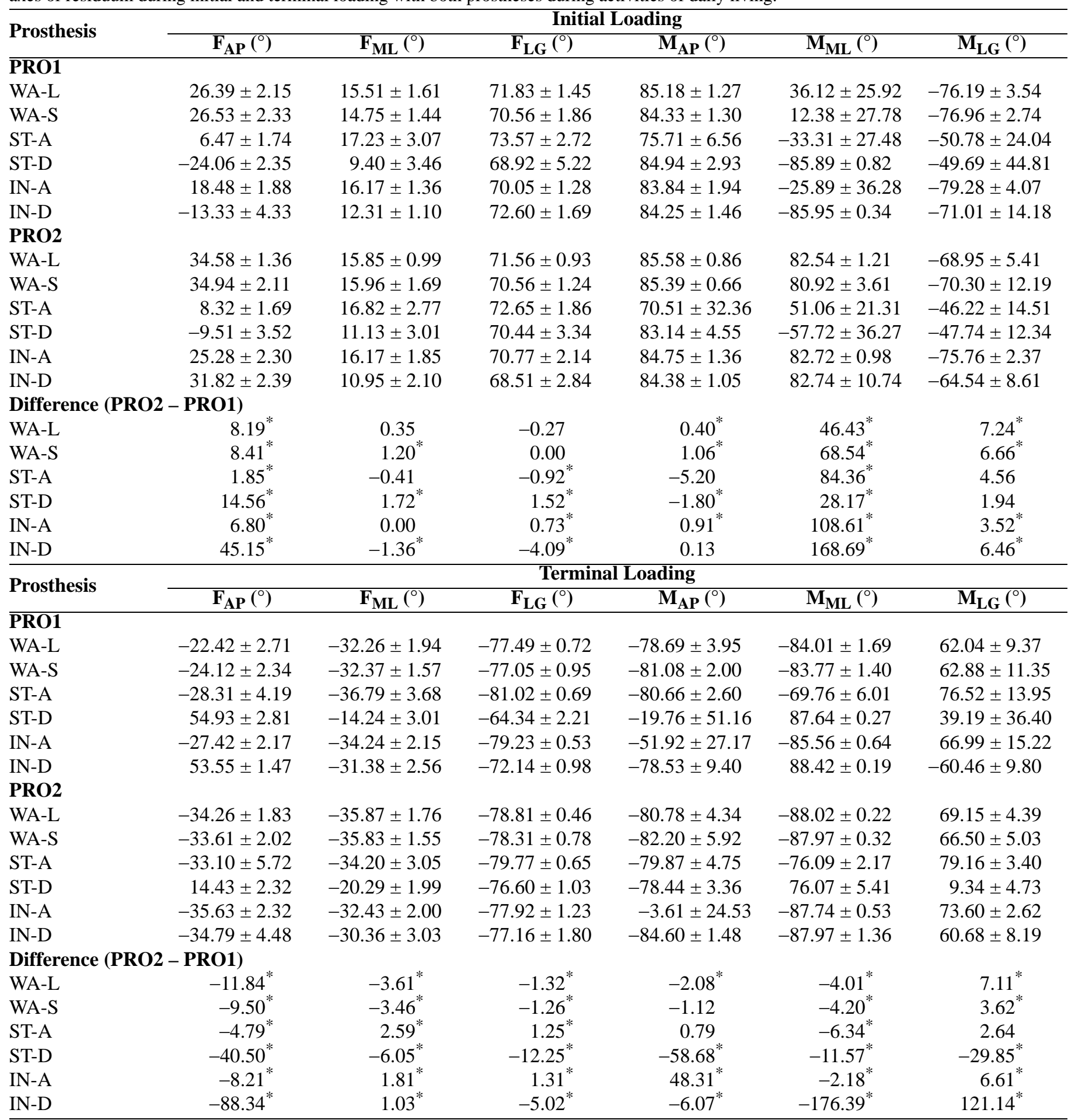

Note: PRO1 consisted of C-Leg (Otto Bock; Vienna, Austria), tube adapter (Otto Bock), and C-Walk foot (model 1C40, Otto Bock). PRO2 consisted of Total Knee (Össur; Reykjavik, Iceland), Total Shock (Össur), tube adapter (Össur), and Trustep (College Park Inc; Warren, Michigan).

*Significantly different $(p<0.05)$.

IN-A = ascending incline, IN-D = descending incline, PRO1 = prosthesis 1 (mechanical), PRO2 = prosthesis 2 (microprocessor-controlled), ST-A = ascending stairs, ST-D = descending stairs, WA-L = walking on long walkway, WA-S = walking on short walkway. 
Table 5.

Mean \pm 1 standard deviation and differences of norm of impulse $\left(\mathrm{I}_{\mathrm{N}}\right)$ and component along anteroposterior (AP), mediolateral (ML), and long (LG) axes of residuum with both prostheses during activities of daily living.

\begin{tabular}{|c|c|c|c|c|}
\hline Prosthesis & $\mathrm{I}_{\mathrm{AP}}$ (Ns) & $\mathbf{I}_{\mathbf{M L}}$ (Ns) & $\mathrm{I}_{\mathrm{LG}}$ (Ns) & $\mathrm{I}_{\mathrm{N}}(\mathrm{Ns})$ \\
\hline \multicolumn{5}{|l|}{$\overline{\text { PRO1 }}$} \\
\hline WA-L & $44.04 \pm 2.69$ & $40.55 \pm 2.92$ & $357.73 \pm 24.81$ & $365.81 \pm 24.98$ \\
\hline WA-S & $47.36 \pm 2.26$ & $45.93 \pm 3.58$ & $398.14 \pm 25.00$ & $406.94 \pm 25.17$ \\
\hline ST-D & $79.77 \pm 5.28$ & $16.10 \pm 3.07$ & $260.61 \pm 21.30$ & $274.18 \pm 20.88$ \\
\hline IN-A & $53.09 \pm 4.05$ & $50.47 \pm 4.04$ & $430.26 \pm 21.85$ & $439.62 \pm 22.17$ \\
\hline WA-L & $55.15 \pm 2.79$ & $49.01 \pm 3.41$ & $390.09 \pm 20.02$ & $400.71 \pm 20.36$ \\
\hline WA-S & $57.66 \pm 3.64$ & $53.28 \pm 3.91$ & $422.40 \pm 20.48$ & $433.57 \pm 20.85$ \\
\hline ST-A & $34.36 \pm 12.49$ & $50.53 \pm 6.45$ & $492.74 \pm 37.08$ & $497.11 \pm 37.57$ \\
\hline ST-D & $26.09 \pm 5.13$ & $23.19 \pm 3.10$ & $319.07 \pm 21.39$ & $321.51 \pm 21.60$ \\
\hline IN-A & $70.46 \pm 4.74$ & $61.02 \pm 4.06$ & $475.41 \pm 22.87$ & $487.95 \pm 23.26$ \\
\hline WA-S & 10.30 & 7.36 & 24.26 & 26.63 \\
\hline ST-A & 4.53 & 6.45 & 32.10 & 32.92 \\
\hline ST-D & -53.68 & 7.08 & 58.46 & 47.33 \\
\hline IN-A & 17.37 & 10.55 & 45.15 & 48.33 \\
\hline IN-D & -2.39 & 16.48 & 138.38 & 139.49 \\
\hline
\end{tabular}

\section{Limits for Generalization}

The generalization of the results was limited mainly because of the typical intrinsic shortcoming of a single-case study as well as the short acclimation time with PRO2 and the small alignment variations. Furthermore, the interpretation of the results is limited by the lack of assessment of confounders associated with spatial variables (e.g., walking base, step and stride length), as well as dynamics (e.g., ground and handrail reaction forces), kinematics (e.g., trunk bending, hip range of movement), and kinetics (e.g., ankle, knee, and hip joint moments and work [28-30]).

\section{Future Studies}

The proposed characterization will facilitate future longitudinal studies comparing prostheses construction (e.g., socket design, components, alignment) for a larger cohort of individuals with TFA fitted with an osseointegrated fixation or socket. This will provide benchmark information, and eventually, a better understanding of intra- and inter-variability between attachments, components, participants, and activities.

The possibilities for cross-sectional studies are endless, particularly for the ones associating the proposed characterization with complementary biomechanical (e.g., dynamics, kinematics, and kinetics characteristics) and physiological (e.g., electromyography of the hip and residuum muscles [52], metabolic energy consumption) data.

\section{CONCLUSIONS}

This was the first attempt to establish to what extent prostheses can be characterized through inner-prosthetic loading applied on the residuum of an individual with TFA during ADLs. This study is a stepping stone in components characterization. It can hopefully provide key information to clinicians facing the challenge of restoring safe function in individuals with a lower-limb amputation, programs, and design of prosthetic components. 


\section{ACKNOWLEDGMENTS}

\section{Author Contributions:}

Study concept and design: L. Frossard.

Acquisition of data: L. Frossard, E. Häggström, R. Brånemark. Analysis and interpretation of data: L. Frossard, E. Häggström, K. Hagberg, R. Brånemark.

Drafting of manuscript: L. Frossard, E. Häggström, K. Hagberg, R. Brånemark.

Critical revision of manuscript for important intellectual content:

L. Frossard, E. Häggström, K. Hagberg, R. Brånemark.

Statistical analysis: L. Frossard.

Obtained funding: L. Frossard, R. Brånemark.

Administrative, technical, or material support: L. Frossard,

R. Brånemark.

Study supervision: L. Frossard, R. Brånemark.

Financial Disclosures: The authors have declared that no conflicts of interest exist.

Funding/Support: This material was based on work supported by the Australian Research Council Discovery Project (grant DP0345667), Australian Research Council Linkage (grant LP0455481), Queensland University of Technology Strategic Link with the Industry and Institute of Health and Biomedical Innovation Advanced Diagnosis in Medical Device Grant, University of Quebec in Montreal Kick-Off grant, and the Marie-Enfant Rehabilitation Centre of CHU Sainte-Justine Centre of Research Kick-Off grant.

Additional Contributions: The authors wish to acknowledge Professor John Evans, Professor Mark Pearcy, and Dr. Roy Tranberg for their valuable contribution to data collection.

Institutional Review: The participant provided informed written consent. The research institution's human ethics committee approved this study.

Participant Follow-up: The authors do plan to inform the participant of the publication of this study. Furthermore, he has been encouraged to check the study Web site for updated publications.

\section{REFERENCES}

1. Pitkin M. On the way to total integration of prosthetic pylon with residuum. J Rehabil Res Dev. 2009;46(3):345-60. [PMID:19675987] http://dx.doi.org/10.1682/JRRD.2008.08.0112

2. Pitkin M. One lesson from arthroplasty to osseointegration in search for better fixation of in-bone implanted prosthesis. J Rehabil Res Dev. 2008;45(4):vii-xiv. [PMID:18712634]

3. Pitkin M. Design features of implants for direct skeletal attachment of limb prostheses. J Biomed Mater Res A. 2013. In press. [PMID:23554122] http://dx.doi.org/10.1002/jbm.a.34606

4. Pendegrass CJ, Goodship AE, Blunn GW. Development of a soft tissue seal around bone-anchored transcutaneous amputation prostheses. Biomaterials. 2006;27(23):4183-91.

\section{[PMID:16618500]}

http://dx.doi.org/10.1016/j.biomaterials.2006.03.041

5. Aschoff HH, Kennon RE, Keggi JM, Rubin LE. Transcutaneous, distal femoral, intramedullary attachment for abovethe-knee prostheses: an endo-exo device. J Bone Joint Surg Am. 2010;92(Suppl 2):180-86. [PMID:21123601] http://dx.doi.org/10.2106/JBJS.J.00806

6. Hagberg K, Brånemark R. One hundred patients treated with osseointegrated transfemoral amputation prosthesesrehabilitation perspective. J Rehabil Res Dev. 2009;46(3): 331-44. [PMID:19675986] http://dx.doi.org/10.1682/JRRD.2008.06.0080

7. Lundberg M, Hagberg K, Bullington J. My prosthesis as a part of me: a qualitative analysis of living with an osseointegrated prosthetic limb. Prosthet Orthot Int. 2011;35(2): 207-14. [PMID:21697203] http://dx.doi.org/10.1177/0309364611409795

8. Frossard L, Gow DL, Hagberg K, Cairns N, Contoyannis B, Gray S, Brånemark R, Pearcy M. Apparatus for monitoring load bearing rehabilitation exercises of a transfemoral amputee fitted with an osseointegrated fixation: a proofof-concept study. Gait Posture. 2010;31(2):223-28.

[PMID:19926285]

http://dx.doi.org/10.1016/j.gaitpost.2009.10.010

9. Frossard LA. Load on osseointegrated fixation of a transfemoral amputee during a fall: Determination of the time and duration of descent. Prosthet Orthot Int. 2010;34(4): 472-87. [PMID:20961183] http://dx.doi.org/10.3109/03093646.2010.520057

10. Frossard LA, Tranberg R, Haggstrom E, Pearcy M, Brånemark R. Load on osseointegrated fixation of a transfemoral amputee during a fall: loading, descent, impact and recovery analysis. Prosthet Orthot Int. 2010;34(1):85-97. [PMID:20196690] http://dx.doi.org/10.3109/03093640903585024

11. Sullivan J, Uden M, Robinson KP, Sooriakumaran S. Rehabilitation of the trans-femoral amputee with an osseointegrated prosthesis: the United Kingdom experience. Prosthet Orthot Int. 2003;27(2):114-20. [PMID:14571941] http:// dx.doi.org/10.1080/03093640308726667

12. Hagberg K, Brånemark R, Gunterberg B, Rydevik B. Osseointegrated trans-femoral amputation prostheses: prospective results of general and condition-specific quality of life in 18 patients at 2-year follow-up. Prosthet Orthot Int. 2008;32(1):29-41. [PMID:18330803]

13. Blumentritt S, Schmalz T, Jarasch R. The safety of C-Leg: Biomechanical tests. J Prosthet Orthot. 2009;21(1):2-15.

14. Brånemark R, Brånemark P-I, Rydevik B, Myers RR. Osseointegration in skeletal reconstruction and rehabilitation: a review. J Rehabil Res Dev. 2001;38(2):175-81. [PMID:11392650] 
15. Orendurff MS, Segal AD, Klute GK, McDowell ML, Pecoraro JA, Czerniecki JM. Gait efficiency using the C-Leg. J Rehabil Res Dev. 2006;43(2):239-46. [PMID:16847790] http://dx.doi.org/10.1682/JRRD.2005.06.0095

16. Seroussi RE, Gitter A, Czerniecki JM, Weaver K. Mechanical work adaptations of above-knee amputee ambulation. Arch Phys Med Rehabil. 1996;77(11):1209-14. [PMID:8931539] http://dx.doi.org/10.1016/S0003-9993(96)90151-3

17. Prinsen EC, Nederhand MJ, Rietman JS. Adaptation strategies of the lower extremities of patients with a transtibial or transfemoral amputation during level walking: a systematic review. Arch Phys Med Rehabil. 2011;92(8):1311-25. [PMID:21714957] http://dx.doi.org/10.1016/j.apmr.2011.01.017

18. Boonstra AM, Schrama JM, Eisma WH, Hof AL, Fidler V. Gait analysis of transfemoral amputee patients using prostheses with two different knee joints. Arch Phys Med Rehabil. 1996;77(5):515-20. [PMID:8629932] http://dx.doi.org/10.1016/S0003-9993(96)90044-1

19. Godfrey CM, Jousse AT, Brett R, Butler JF. A comparison of some gait characteristics with six knee joints. Orthot Prosthet. 1975;29(3):33-38.

20. Murray MP, Mollinger LA, Sepic SB, Gardner GM, Linder MT. Gait patterns in above-knee amputee patients: hydraulic swing control vs constant-friction knee components. Arch Phys Med Rehabil. 1983;64(8):339-45. [PMID:6882172]

21. Michael JW. Modern prosthetic knee mechanisms. Clin Orthop Relat Res. 1999;361(361):39-47.

[PMID:10212594]

22. Sagawa Y Jr, Turcot K, Armand S, Thevenon A, Vuillerme N, Watelain E. Biomechanics and physiological parameters during gait in lower-limb amputees: a systematic review. Gait Posture. 2011;33(4):511-26. [PMID:21392998] http://dx.doi.org/10.1016/j.gaitpost.2011.02.003

23. Klute GK, Kallfelz CF, Czerniecki JM. Mechanical properties of prosthetic limbs: adapting to the patient. J Rehabil Res Dev. 2001;38(3):299-307. [PMID:11440261]

24. Barr JB, Wutzke CJ, Threlkeld AJ. Longitudinal gait analysis of a person with a transfemoral amputation using three different prosthetic knee/foot pairs. Physiother Theory Pract. 2012;28(5):407-11. [PMID:22191438] http://dx.doi.org/10.3109/09593985.2011.631695

25. Sapin E, Goujon H, de Almeida F, Fodé P, Lavaste F. Functional gait analysis of trans-femoral amputees using two different single-axis prosthetic knees with hydraulic swingphase control: Kinematic and kinetic comparison of two prosthetic knees. Prosthet Orthot Int. 2008;32(2):201-18. [PMID:18569888] http://dx.doi.org/10.1080/03093640802016639
26. Stephenson P, Seedhom BB. Estimation of forces at the interface between an artificial limb and an implant directly fixed into the femur in above-knee amputees. J Orthop Sci. 2002;7(3):292-97. [PMID:12077652] http://dx.doi.org/10.1007/s007760200050

27. Miller LA, Childress DS. Problems associated with the use of inverse dynamics in prosthetic applications: An example using a polycentric prosthetic knee. Robotica. 2005;23(3): 329-35. http://dx.doi.org/10.1017/S0263574704001353

28. Frossard L, Cheze L, Dumas R. Dynamic input to determine hip joint moments, power and work on the prosthetic limb of transfemoral amputees: ground reaction vs knee reaction. Prosthet Orthot Int. 2011;35(2):140-49.

[PMID:21697197] http://dx.doi.org/10.1177/0309364611409002

29. Dumas R, Cheze L, Frossard L. Loading applied on prosthetic knee of transfemoral amputee: comparison of inverse dynamics and direct measurements. Gait Posture. 2009;30(4):560-62. [PMID:19709886] http://dx.doi.org/10.1016/j.gaitpost.2009.07.126

30. Dumas R, Cheze L, Frossard LA. Load during prosthetic gait: Is direct measurement better than inverse dynamics? Gait Posture. 2009;30(Suppl 2):S86-87.

http://dx.doi.org/10.1016/j.gaitpost.2009.08.128

31. Neumann ES, Yalamanchili K, Brink J, Lee JS. Transducer-based comparisons of the prosthetic feet used by transtibial amputees for different walking activities: a pilot study. Prosthet Orthot Int. 2012;36(2):203-16.

[PMID:22344316] http://dx.doi.org/10.1177/0309364612436408

32. Frossard L, Beck J, Dillon M, Chappell M, Evans JH. Development and preliminary testing of a device for the direct measurement of forces and moments in the prosthetic limb of transfemoral amputees during activities of daily living. J Prosthet Orthot. 2003;15(4):135-42.

33. Frossard L, Hagberg K, Haggstrom E, Branemark R. Loadrelief of walking AIDS on osseointegrated fixation: instrument for evidence-based practice. IEEE Trans Neural Syst Rehabil Eng. 2009;17(1):9-14. [PMID:19211318] http://dx.doi.org/10.1109/TNSRE.2008.2010478

34. Lee WC, Frossard LA, Hagberg K, Haggstrom E, Gow DL, Gray S, Brånemark R. Magnitude and variability of loading on the osseointegrated implant of transfemoral amputees during walking. Med Eng Phys. 2008;30(7):825-33. [PMID:17977050] http://dx.doi.org/10.1016/j.medengphy.2007.09.003

35. Lee WC, Frossard LA, Hagberg K, Haggstrom E, Brånemark R, Evans JH, Pearcy MJ. Kinetics of transfemoral amputees with osseointegrated fixation performing common activities of daily living. Clin Biomech (Bristol, Avon). 2007;22(6):665-73. [PMID:17400346] http://dx.doi.org/10.1016/j.clinbiomech.2007.02.005 
36. Frossard L, Stevenson N, Sullivan J, Uden M, Pearcy M. Categorization of activities of daily living of lower limb amputees during short-term use of a portable kinetic recording system: A preliminary study. J Prosthet Orthot. 2011;23(1):2-11.

37. Frossard L, Stevenson N, Smeathers J, Häggström E, Hagberg K, Sullivan J, Ewins D, Gow DL, Gray S, Brånemark R. Monitoring of the load regime applied on the osseointegrated fixation of a trans-femoral amputee: a tool for evidence-based practice. Prosthet Orthot Int. 2008;32(1): 68-78. [PMID:18330805]

http://dx.doi.org/10.1080/03093640701676319

38. Bellmann M, Schmalz T, Blumentritt S. Comparative biomechanical analysis of current microprocessor-controlled prosthetic knee joints. Arch Phys Med Rehabil. 2010;91(4): 644-52. [PMID:20382300] http://dx.doi.org/10.1016/j.apmr.2009.12.014

39. Bellmann M, Schmalz T, Ludwigs E, Blumentritt S. Immediate effects of a new microprocessor-controlled prosthetic knee joint: a comparative biomechanical evaluation. Arch Phys Med Rehabil. 2012;93(3):541-49. [PMID:22373937] http://dx.doi.org/10.1016/j.apmr.2011.10.017

40. Blumentritt S, Scherer H, Michael J, Schmalz T. Transfemoral amputees walking on a rotary hydraulic prosthetic knee mechanism: A preliminary report. J Prosthet Orthot. 1998; 10(3):61-70.

41. Frossard L, Tranberg R, Haggstrom E, Pearcy M, Branemark R. Fall of a transfemoral amputee fitted with osseointegrated fixation: loading impact on residuum. Gait Posture. 2009;30(Suppl 2):S151-52.

http://dx.doi.org/10.1016/j.gaitpost.2009.08.227

42. Theeven P, Hemmen B, Rings F, Meys G, Brink P, Smeets R, Seelen H. Functional added value of microprocessorcontrolled knee joints in daily life performance of Medicare Functional Classification Level-2 amputees. J Rehabil Med. 2011;43(10):906-15. [PMID:21947182]

43. Theeven P, Hemmen B, Stevens C, Ilmer E, Brink P, Seelen H. Feasibility of a new concept for measuring actual functional performance in daily life of transfemoral amputees. J Rehabil Med. 2010;42(8):744-51. [PMID:20809056] http://dx.doi.org/10.2340/16501977-0591

44. Frossard L, Hagberg K, Haggstrom E, Lee Gow D, Branemark R, Pearcy M. Functional outcome of transfemoral amputees fitted with an osseointegrated fixation: Temporal gait characteristics. J Prosthet Orthot. 2010;22(1):11-20.

45. Helgason B, Pálsson H, Rúnarsson TP, Frossard L, Viceconti M. Risk of failure during gait for direct skeletal attachment of a femoral prosthesis: a finite element study. Med Eng Phys. 2009;31(5):595-600. [PMID:19150253] http://dx.doi.org/10.1016/j.medengphy.2008.11.015

46. Lee WC, Doocey JM, Brånemark R, Adam CJ, Evans JH, Pearcy MJ, Frossard LA. FE stress analysis of the interface between the bone and an osseointegrated implant for ampu- tees-implications to refine the rehabilitation program. Clin Biomech (Bristol, Avon). 2008;23(10):1243-50.

[PMID:18809231]

http://dx.doi.org/10.1016/j.clinbiomech.2008.06.012

47. van der Linde H, Hofstad CJ, Geurts AC, Postema K, Geertzen JH, van Limbeek J. A systematic literature review of the effect of different prosthetic components on human functioning with a lower-limb prosthesis. J Rehabil Res Dev. 2004;41(4):555-70. [PMID:15558384]

http://dx.doi.org/10.1682/JRRD.2003.06.0102

48. Nair A, Hanspal RS, Zahedi MS, Saif M, Fisher K. Analyses of prosthetic episodes in lower limb amputees. Prosthet Orthot Int. 2008;32(1):42-49. [PMID:17943622]

http://dx.doi.org/10.1080/03093640701610615

49. Burnfield JM, Eberly VJ, Gronely JK, Perry J, Yule WJ, Mulroy SJ. Impact of stance phase microprocessor-controlled knee prosthesis on ramp negotiation and community walking function in K2 level transfemoral amputees. Prosthet Orthot Int. 2012;36(1):95-104. [PMID:22223685] http://dx.doi.org/10.1177/0309364611431611

50. Collins DM, Karmarkar A, Relich R, Pasquina PF, Cooper RA. Review of research on prosthetic devices for lower extremity amputation. Crit Rev Biomed Eng. 2006;34(5): 379-438. [PMID:17206920] http://dx.doi.org/10.1615/CritRevBiomedEng.v34.i5.20

51. Rosenbaum TG, Bloebaum RD, Ashrafi S, Lester DK. Ambulatory activities maintain cortical bone after total hip arthroplasty. Clin Orthop Relat Res. 2006;450:129-37. [PMID:16721349]

52. Pantall A, Durham S, Ewins D. Surface electromyographic activity of five residual limb muscles recorded during isometric contraction in transfemoral amputees with osseointegrated prostheses. Clin Biomech (Bristol, Avon). 2011;26(7):760-65. [PMID:21474221] http://dx.doi.org/10.1016/j.clinbiomech.2011.03.008

Submitted for publication April 10, 2012. Accepted in revised form November 28, 2012.

This article and all supplementary material should be cited as follows:

Frossard L, Häggström E, Hagberg K, Brånemark R. Load applied on bone-anchored transfemoral prosthesis: Characterization of a prosthesis-A pilot study. J Rehabil Res Dev. 2013;50(5):619-34.

http://dx.doi.org/10.1682/JRRD.2012.04.0062

ResearcherID/ORCID: Laurent Frossard, PhD: C-3582-2008

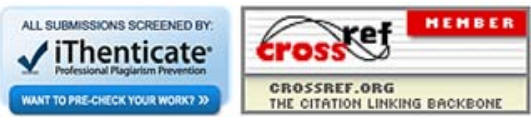

